\title{
STUDIES ON DIGITALIS. IX. EFFECTS OF OUABAIN ON THE NONFAILING HUMAN HEART
}

\author{
By DEAN T. MASON ANd EUGENE BRAUNWALD
}

(From the Cardiology Branch, National Heart Institute, Bethesda, Md.)

(Submitted for publication December 31, 1962; accepted March 21, 1963)

In spite of the widespread use of digitalis in clinical medicine and the extensive experimental work that has been carried out with this drug, its action on the nonfailing human heart still requires clarification. A variety of experiments on openchest, presumably normal, anesthetized dogs has clearly shown that digitalis glycosides have a positive inotropic action (1-4). The applicability of these observations to the normal heart in intact human subjects is limited because the possibility cannot be excluded that depression of myocardial contractility by the anesthetic agents and the surgical exposure of the heart modified the response to the digitalis glycoside in the animal experiments. Hemodynamic studies in subjects with normal hearts and in patients with heart disease without congestive heart failure have suggested that digitalis does not improve myocardial contractility, and may even have a depressing effect, since its administration results either in no change in the cardiac output, or in a decline (5-9). It is now clear that measurement of the cardiac output alone does not necessarily provide an assessment of ventricular contractility (10). The unavailability, in the past, of a reliable method for studying contractility in the hearts of intact human subjects has been responsible for the lack of information concerning the crucial question of how digitalis affects the normal, or the diseased but nonfailing human heart.

Recently, Sarnoff and Mitchell have defined myocardial contractility as follows: "When from any given end-diastolic pressure or fiber length, the ventricle produces more external stroke work and more external stroke power, an increase in ventricular contractility is said to have taken place. Implicit in this definition is an increased rate of development of tension when contractility increases" (11). Rushmer has also found that an increased ventricular contractility is reflected by an increase in the peak rate of development of in- traventricular pressure (12). The observations of these and other investigators $(1,4,13-19)$ are all compatible with the view that the rate at which ventricular pressure rises during isometric contraction is determined by the contractile state of the myocardium and by the conditions under which the ventricle contracts, i.e., the ventricular enddiastolic pressure, arterial pressure, and heart rate.

In 1927, Wiggers and Stimson demonstrated that digitalis resulted in a more rapid rise of left ventricular pressure in the dog, and they concluded that, like epinephrine, the glycosides improve myocardial contraction $(1,16)$. Measurement of the instantaneous rate of rise of intraventricular pressure in man has been fraught with considerable difficulty because of the serious artifacts in the pressure tracings obtained at cardiac catheterization by the standard catheter-manometer systems. The recent development of a cardiac catheter with a high-fidelity micromanometer mounted at its tip (20), however, has largely solved this problem, since it is now possible with this instrument to record intraventricular pressure pulses faithfully and without significant distortion. In a previous communication from this laboratory, the use of the continuously computed rate of change of intraventricular pressure in assessing the functional status of the heart in man was presented (21). The objective of the present investigation was to apply this technic in the determination of the effects of a cardiac glycoside, ouabain, on the normal and on the diseased but nonfailing human ventricle.

\section{SUBJECTS AND METHODS}

The effects of ouabain were determined in a total of ten patients who ranged in age between 14 and 45 years. The rate of change $(\mathrm{dp} / \mathrm{dt})$ in the right ventricular pressure pulse was studied in six patients after detailed clinical examination, as well as right and left heart catheterization, had been carried out. Four of these subjects, who were referred because of precordial systolic mur- 
murs, were considered to have normal cardiovascular systems. One patient, W.A., was studied 1 year following successful closure of an atrial septal defect, and the clinical and hemodynamic studies did not reveal any abnormalities. The sixth patient, R.B., had a small coronary arteriovenous fistula emptying into the pulmonary artery. The pressures in the right side of the heart were within normal limits. There was no cardiac enlargement or diminished cardiac reserve, and the shunt into the pulmonary artery was so small that it could not be detected by the inhaled $\mathrm{Kr}^{85}$ test (22) or by selective angiocardiography. The effects of ouabain on the $\mathrm{dp} / \mathrm{dt}$ of the left ventricular pressure pulse was determined in four patients who had uncomplicated ostium secundum atrial septal defects; the presence of the interatrial communication permitted passage of the catheter into the left ventricle. None of these four patients had ever experienced congestive heart failure. Although they did not have normal hearts, their left ventricular end-diastolic pressures were within normal limits (23), and their atrial septal defects were not considered to have placed an abnormal hemodynamic burden on their left ventricles.

All studies were performed with the patient in the basal, postabsorptive state. After placement of the catheter into the ventricle, 15 minutes were permitted to elapse for the patient to reach a stable state. Three control measurements of intraventricular pressures and the $\mathrm{dp} / \mathrm{dt}$ of the right (or left) ventricular pressure pulse were then made at 5 -minute intervals. Ouabain, $0.30 \mathrm{mg}$ to $0.60 \mathrm{mg}$, representing doses ranging between $.0076 \mathrm{mg}$ per $\mathrm{kg}$ and $.0126 \mathrm{mg}$ per $\mathrm{kg}$ (average $=.0096 \mathrm{mg}$ per $\mathrm{kg}$ ), was then infused through the cardiac catheter over a 10-minute period. Measurements of ventricular pressure and $\mathrm{dp} / \mathrm{dt}$ of the right (or left) ventricular pressure pulse were carried out at 5-minute intervals for the next 60 minutes.

The methods of recording intraventricular pressure and $\mathrm{dp} / \mathrm{dt}$ have been presented in detail previously (21). Briefly, a Telco intracardiac micromanometer was employed. This manometer has been shown to maintain a uniform response to frequencies as high as 200 cycles per second (21). The $\mathrm{dp} / \mathrm{dt}$ of ventricular pressure was continuously determined with an R-C differentiating circuit having a time constant of $9.4 \times 10^{-5}$ seconds, which provided differentiation of linear amplitude without phase distortion to 50 cycles per second (24).

\section{RESULTS}

The results are presented in Table $\mathrm{I}$. The means of the three values of the peak $d p / d t d e-$

TABLE I

Circulatory effects of ouabain*

\begin{tabular}{|c|c|c|c|c|c|c|c|c|c|}
\hline Patient & Age & Weight & Diagnosis & $\begin{array}{c}\text { Ouabain } \\
\text { dose }\end{array}$ & $\begin{array}{l}\text { Condi- } \\
\text { tion }\end{array}$ & $\begin{array}{l}\text { Vent. } \\
\text { peak } \\
\mathrm{dp} / \mathrm{dt}\end{array}$ & $\begin{array}{c}\text { Heart } \\
\text { rate }\end{array}$ & $\begin{array}{l}\text { Vent. } \\
\text { press. } \\
\text { s/d }\end{array}$ & $\begin{array}{l}\text { Intensi- } \\
\text { fication } \\
\text { of pre- } \\
\text { systolic } \\
\mathrm{dp} / \mathrm{dt}\end{array}$ \\
\hline & $y r s$ & $\mathrm{~kg}$ & & $m g$ & & $\underset{\mathrm{sec}}{m m^{\prime} \mathrm{Hg}}$ & $\begin{array}{c}\text { beats/ } \\
\text { min }\end{array}$ & $m m \mathrm{Hg}$ & \\
\hline $\begin{array}{l}\text { Right ventricle } \\
\text { J.B. }\end{array}$ & 14 & 32.0 & Normal & 0.3 & $\begin{array}{l}\text { C } \\
\text { O }\end{array}$ & $\begin{array}{l}235 \\
412\end{array}$ & $\begin{array}{l}111 \\
109\end{array}$ & $\begin{array}{l}23 / 2 \\
25 / 2\end{array}$ & + \\
\hline M.P. & 45 & 65.9 & Normal & 0.6 & $\begin{array}{l}\text { C } \\
\text { O }\end{array}$ & $\begin{array}{l}191 \\
210\end{array}$ & $\begin{array}{l}83 \\
73\end{array}$ & $\begin{array}{l}17 / 3 \\
18 / 3\end{array}$ & + \\
\hline J.M. & 45 & 74.9 & Normal & 0.6 & $\begin{array}{l}\text { C } \\
\text { Ó }\end{array}$ & $\begin{array}{l}140 \\
176\end{array}$ & $\begin{array}{l}67 \\
67\end{array}$ & $\begin{array}{l}24 / 6 \\
27 / 6\end{array}$ & + \\
\hline W.B. & 23 & 61.0 & Normal & 0.5 & $\begin{array}{l}\mathrm{C} \\
\mathrm{O}\end{array}$ & $\begin{array}{l}180 \\
224\end{array}$ & $\begin{array}{l}88 \\
88\end{array}$ & $\begin{array}{l}17 / 2 \\
18 / 2\end{array}$ & - \\
\hline W.A. & 14 & 48.5 & POASD & 0.4 & $\begin{array}{l}\mathrm{C} \\
\mathrm{O}\end{array}$ & $\begin{array}{l}162 \\
207\end{array}$ & $\begin{array}{l}83 \\
83\end{array}$ & $\begin{array}{l}25 / 4 \\
30 / 4\end{array}$ & - \\
\hline R.B. & 35 & 79.4 & $\begin{array}{l}\text { Cor. A-V } \\
\text { fist. }\end{array}$ & 0.5 & $\begin{array}{l}\mathrm{C} \\
\mathrm{O}\end{array}$ & $\begin{array}{l}291 \\
348\end{array}$ & $\begin{array}{l}83 \\
73\end{array}$ & $\begin{array}{l}18 / 3 \\
20 / 3\end{array}$ & - \\
\hline Average & & & & & $\begin{array}{l}\mathrm{C} \\
\mathrm{O}\end{array}$ & $\begin{array}{l}200 \\
263\end{array}$ & $\begin{array}{l}86 \\
82\end{array}$ & $\begin{array}{l}21 / 3 \\
23 / 3\end{array}$ & \\
\hline $\begin{array}{c}\text { Left ventricle } \\
\text { V.Z. }\end{array}$ & 40 & 47.5 & ASD & 0.6 & $\begin{array}{l}\text { C } \\
\text { O }\end{array}$ & $\begin{array}{l}677 \\
870\end{array}$ & $\begin{array}{l}82 \\
73\end{array}$ & $\begin{array}{l}90 / 6 \\
99 / 6\end{array}$ & + \\
\hline L.F. & 23 & 53.0 & ASD & 0.6 & $\begin{array}{l}\mathrm{C} \\
\mathrm{O}\end{array}$ & $\begin{array}{r}755 \\
1,000\end{array}$ & $\begin{array}{l}64 \\
58\end{array}$ & $\begin{array}{r}94 / 4 \\
114 / 4\end{array}$ & - \\
\hline R.N. & 32 & 58.8 & ASD & 0.6 & $\stackrel{\text { C }}{\text { o }}$ & $\begin{array}{l}1,005 \\
1,495\end{array}$ & $\begin{array}{l}102 \\
102\end{array}$ & $\begin{array}{l}100 / 3 \\
104 / 3\end{array}$ & - \\
\hline R.M. & 16 & 53.9 & ASD & 0.6 & $\begin{array}{l}\mathrm{C} \\
\mathrm{O}\end{array}$ & $\begin{array}{l}685 \\
865\end{array}$ & $\begin{array}{l}77 \\
77\end{array}$ & $\begin{array}{r}90 / 7 \\
120 / 3\end{array}$ & - \\
\hline Average & & & & & $\begin{array}{l}\mathrm{C} \\
\mathrm{O}\end{array}$ & $\begin{array}{r}781 \\
1,058\end{array}$ & $\begin{array}{l}81 \\
78\end{array}$ & $\begin{array}{r}94 / 5 \\
109 / 4\end{array}$ & \\
\hline
\end{tabular}

* Abbreviations: $\mathrm{dp} / \mathrm{dt}=$ rate of change; vent. press. = ventricular pressure; $\mathrm{s} / \mathrm{d}=$ systolic/diastolic; $\mathrm{C}=$ control observation before ouabain; $\mathrm{O}=$ observation after ouabain; + indicates intensification of presystolic $\mathrm{dp} / \mathrm{dt}$; - indicates no intensification of presystolic $\mathrm{dp} / \mathrm{dt}$; POASD = postoperative atrial septal defect; Cor. A-V Fist. = small coronary arteriovenous fistula; ASD $=$ atrial septal defect. 
termined during the control period are shown. There was little variation among these three values recorded in any given subject before the infusion of ouabain; the average deviation of the single measurements from the patient's mean value ranged from 0 to $6.6 \%$ and averaged $2.0 \%$ of the mean value in the ten patients studied.

In the six patients in whom the effects of ouabain on the right ventricular peak $\mathrm{dp} / \mathrm{dt}$ were determined, the average values for this variable during the control period ranged between $140 \mathrm{~mm}$ $\mathrm{Hg}$ per second and $291 \mathrm{~mm} \mathrm{Hg}$ per second. An increase in the peak $\mathrm{dp} / \mathrm{dt}$ occurred in every patient, and the effect was usually appreciable by 10 minutes after the onset of injection. The maximal increases were noted between 25 and $60 \mathrm{~min}$ utes (average $=42$ minutes) following the onset of the injection of the drug. The maximal value for the peak $\mathrm{dp} / \mathrm{dt}$ exceeded the average of the control values by between $19 \mathrm{~mm} \mathrm{Hg}$ per second and $177 \mathrm{~mm} \mathrm{Hg}$ per second, an increase that averaged $63 \mathrm{~mm} \mathrm{Hg}$ per second in the six subjects. Expressed as a percentage, the maximal value for the peak $\mathrm{dp} / \mathrm{dt}$ exceeded the average of the control values by between 9.9 and $75.3 \%$, an increase that averaged $31.5 \%$ of the control values in the six subjects. The changes in the peak $\mathrm{dp} / \mathrm{dt}$ following the administration of ouabain to one of these patients, J.B., are illustrated in Figure 1.

In the four patients in whom the effects of ouabain on the left ventricular peak $\mathrm{dp} / \mathrm{dt}$ were studied, the average of the peak values for this variable during the control period ranged between $677 \mathrm{~mm}$ $\mathrm{Hg}$ per second and $1,005 \mathrm{~mm} \mathrm{Hg}$ per second. An increase in the peak dp/dt occurred in every patient and became maximal between 20 and 50 minutes (average $=33$ minutes) following the onset of the injection of the drug. The maximal $\mathrm{dp} / \mathrm{dt}$ exceeded the average of the control values by between $180 \mathrm{~mm} \mathrm{Hg}$ per second and $490 \mathrm{~mm}$ $\mathrm{Hg}$ per second (average $=277 \mathrm{~mm} \mathrm{Hg}$ per second). Expressed as a percentage, the maximal peak $\mathrm{dp} / \mathrm{dt}$ exceeded the average of the control values by between 26.3 and $48.8 \%$ (average $=$ $35.5 \%$ ). The recording of $\mathrm{dp} / \mathrm{dt}$ before and after ouabain in one of these patients, R.N., is illustrated in Figure 2.

In five of the ten patients, a small presystolic elevation of the ventricular $\mathrm{dp} / \mathrm{dt}$ either became

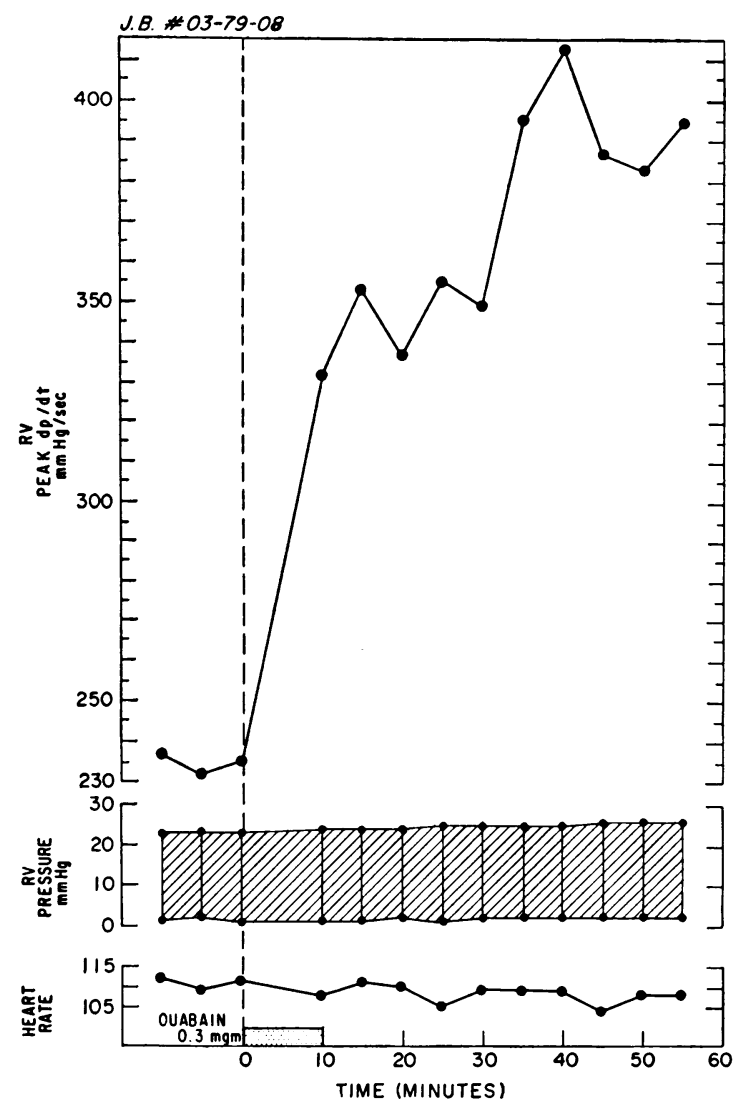

Fig. 1. Sequential measurements of the peak RATE OF CHANGE (dp/dt) OF RIGHT VENTRICULAR (RV) PRESSURE IN PATIENT J.B.

more prominent following ouabain (Figure 3 ) or appeared for the first time (Figure 4). These deflections, which followed the $\mathrm{P}$ wave of the electrocardiogram and occurred during atrial contraction, were followed by a return of the $\mathrm{dp} / \mathrm{dt}$ to 0 before its major elevation during ventricular contraction. These deflections were too small to be measured with accuracy.

\section{DISCUSSION}

During the past several years, increasing evidence has been obtained which suggests that digitalis may exert a positive inotropic effect on the normal and the diseased but nonfailing human heart. Weissler and Grode (25) and Weissler and Warren (26) have reported that cardiac glycosides shorten the duration of mechanical systole, as determined from the phonocardiogram. In patients with heart disease but without heart failure undergoing cardiac operations, it has been 
R.N. \# 03-94-58

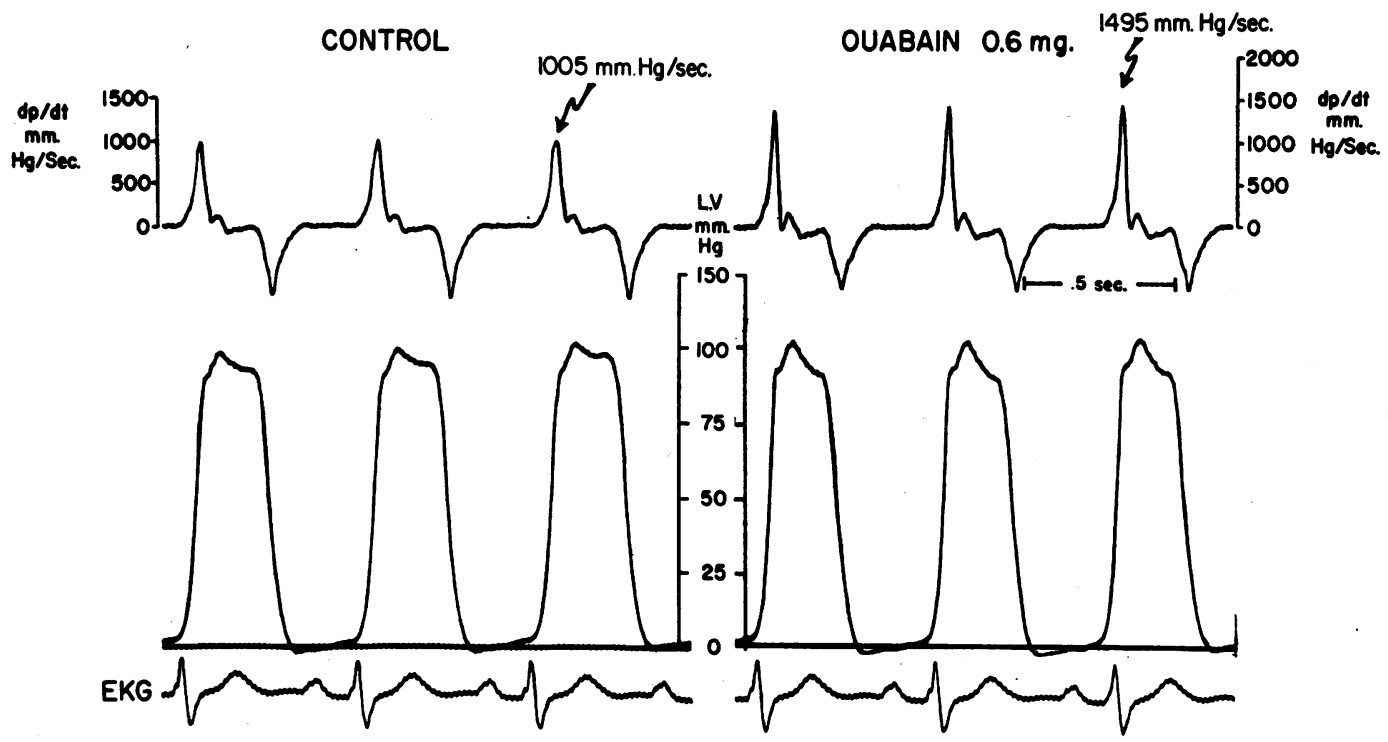

Fig. 2. Recordings of left ventricular (LV) PRessure and RAte of Change (dp/dt) Before ANd 30 MINUTES AFTER OUABAIN ADMINISTRATION.

shown that cardiac glycosides augment the force of contraction, as measured with a myocardial strain-gauge arch (27). Since the strain-gauge arch was sewn to a segment of myocardium that was stretched by approximately $50 \%$ of its resting length, the reactions of the myocardial segment

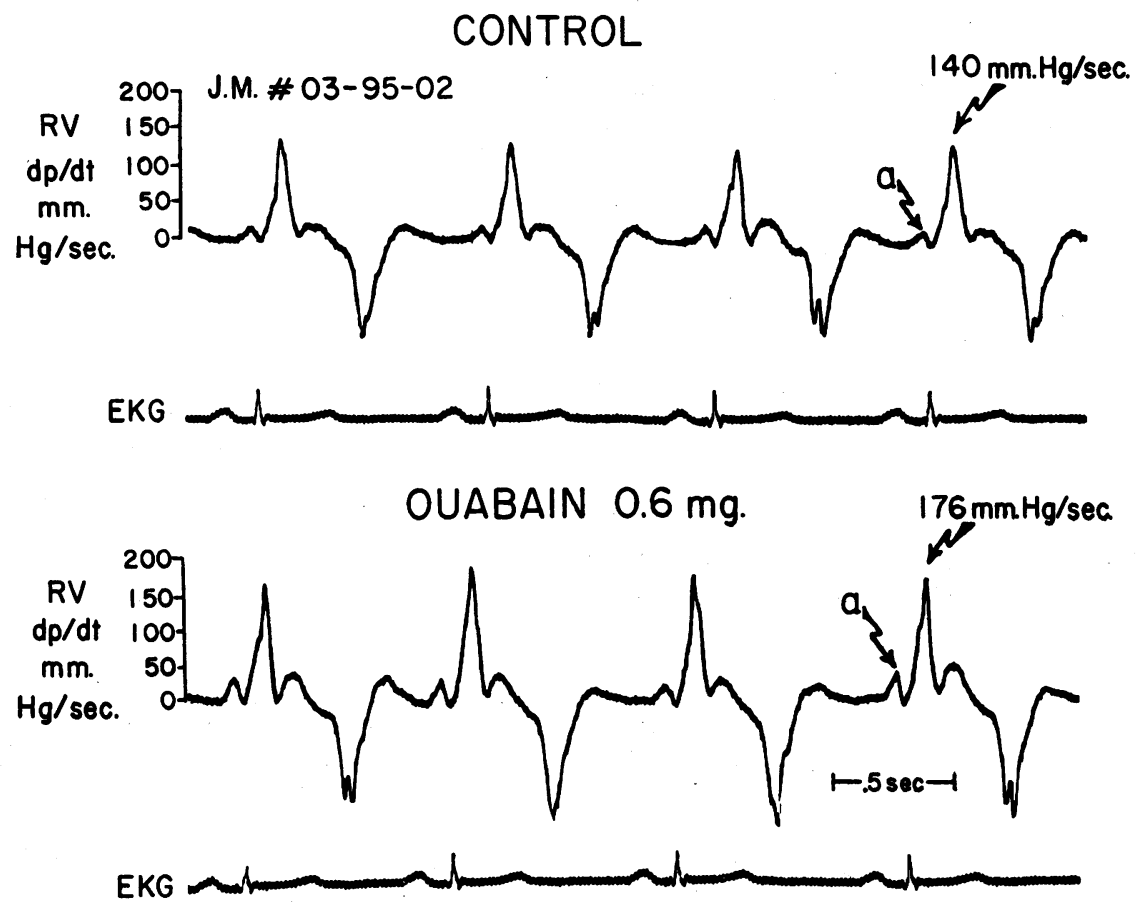

Fig. 3. Recording of FIRSt DeRIVAtive (dp/dt) of RIght Ventricular (RV) PRESSURE PULSE DURING CONTROL PERIOD (TOP) AND 25 MINUTES AFTER OUABAIN ADMINISTRATION (вотTOM). Letter $a$ indicates the presystolic augmentation of the $\mathrm{dp} /$. dt during atrial systole, which became more prominent after ouabain. 
might not be representative of the reaction of the remainder of the ventricle. Furthermore, since the studies were carried out in patients with heart disease, under the conditions of general anesthesia with the chest and pericardium opened during total cardiopulmonary bypass and with the heart empty, the direct applicability of these observations to the unanesthetized intact patient was, of necessity, limited. The demonstration that digoxin diminished the total postexercise oxygen debt of patients with heart disease but without heart failure suggested the possibility that digitalis may be helpful in the clinical management of some of these patients (28). This study, however, also did not resolve the question of whether or not digitalis stimulates the normal or near normal heart of intact, unanesthetized individuals. Accordingly, the present investigation was undertaken.

In every patient, an increase in the rate of intraventricular pressure development (peak $\mathrm{dp} / \mathrm{dt}$ ) was noted, and this finding is interpreted to indicate that the glycoside exhibited a positive inotropic effect. It is now clearly appreciated that hemodynamic influences, besides the functional state of the myocardium, can affect the peak $\mathrm{dp} / \mathrm{dt}$ (4). These influences are the heart rate, the ventricular end-diastolic pressure and volume, and the arterial diastolic pressure. Measurement of the peak dp/dt, however, is particularly suited for assessing the inotropic actions of digitalis in nonfailing hearts, since this drug does not appreciably alter these variables. Indeed, the slight slowing of the heart rate that occurred in five of the ten subjects would, by itself, tend to diminish the peak dp/dt. Ventricular end-diastolic pressures remained unchanged after ouabain. Ventricular end-diastolic volume, however, was not measured, and a change in this variable resulting from an alteration of ventricular compliance induced by ouabain cannot be completely excluded. The diastolic pressures in the pulmonary artery and the aorta were not measured in this investigation. However, the effects of acute digitalization on these pressures in patients without heart failure have been reported by a number of investigators $(7,29-32)$, and no consistent changes have been observed. Although systolic systemic arterial pressure usually rises, the diastolic pressure shows little alteration, presumably because of the con-

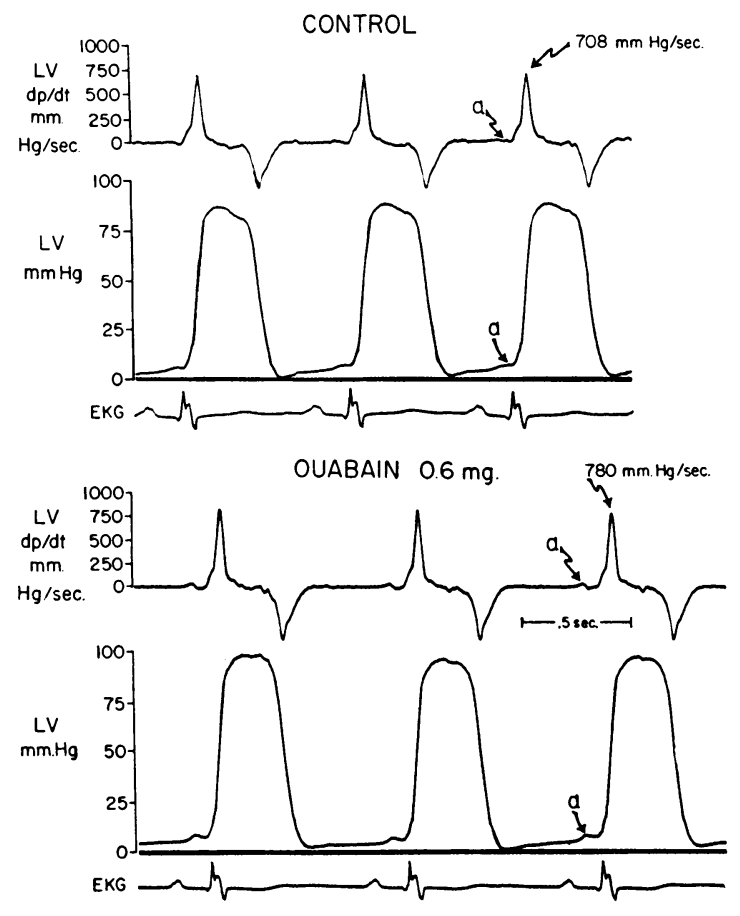

Fig. 4. Simultaneous Recordings of left ventricuLAR (LV) PRESSURE AND OF LEFT VENTRICULAR RATE OF CHANGE (dp/dt) DURING CONTROL PERIOD (TOP) AND AFter OUABain administration (вотtom). The presystolic augmentation of ventricular pressure, $a$, is barely perceptible before ouabain, but becomes clearly evident in the tracings recorded 35 minutes after the administration of the drug.

comitant slowing of heart rate. For the reasons outlined above, it is felt that the large and consistent elevations of the peak $\mathrm{dp} / \mathrm{dt}$ that were observed in every patient can be attributed principally to a direct stimulating effect of ouabain on ventricular contraction. The development or intensification of a small, positive ventricular $\mathrm{dp} / \mathrm{dt}$ during atrial systole in some patients suggests the possibility that this drug also stimulates the force of atrial contraction, resulting in a more rapid rise of intraventricular pressure during atrial systole.

\section{SUM M ARY}

In four patients without heart disease and in two patients with minimal cardiac abnormalities and normal right ventricular function, 0.30 to 0.60 mg ouabain elevated the right ventricular peak rate of change $(\mathrm{dp} / \mathrm{dt}$ ) by 9.9 to $75.3 \%$ (average $=31.5 \%$ ) of control values. In four patients 
with uncomplicated atrial septal defects, in whom the left ventricular hemodynamic burden and left ventricular function were normal, $0.60 \mathrm{mg}$ ouabain elevated the left ventricular peak $\mathrm{dp} / \mathrm{dt}$ by 26.3 to $48.8 \%$ (average $=35.5 \%$ ) of control values. These observations in intact, unanesthetized subjects indicate that ouabain is capable of stimulating the contractility of the nonfailing and of the normal human heart.

\section{REFERENCES}

1. Wiggers, C. J., and B. Stimson. Studies on cardiodynamic actions of drugs. III. Mechanism of cardiac stimulation by digitalis and g-strophanthin. J. Pharmacol. exp. Ther. 1927, 30, 251.

2. Walton, R. P., J. S. Leary, and H. P. Jones. Comparative increase in ventricular contractile force produced by several cardiac glycosides. J. Pharmacol. exp. Ther. 1950, 98, 346.

3. Cotten, M. deV., and P. E. Stopp. Action of digitalis on the nonfailing heart of the dog. Amer. J. Physiol. 1958, 192, 114.

4. Wallace, A. G., N. S. Skinner, and J. H. Mitchell. Hemodynamic determinants of the maximal rate of rise of left ventricular pressure. Amer. J. Physiol. In press.

5. Burwell, C. S., DeW. Neighbors, and E. M. Regen. The effect of digitalis upon the output of the heart in normal man. J. clin. Invest. 1927, 5, 125.

6. Stewart, H. J., and A. E. Cohn. Studies on the effect of the action of digitalis on the output of blood from the heart. III. J. clin. Invest. 1932, $11,917$.

7. Harvey, R. M., M. I. Ferrer, R. T. Cathcart, and J. K. Alexander. Some effects of digoxin on the heart and circulation in man; digoxin in enlarged hearts not in clinical congestive failure. Circulation 1951, 4, 366.

8. Rodman, T., C. A. Gorcxyca, and B. H. Pastor. The effect of digitalis on the cardiac output of the normal heart at rest and during exercise. Ann. intern. Med. 1961, 55, 620.

9. Goodyer, A. V. N., A. Chetrick, and A. Huvos. The effect of Lanatoside-C on the response of the human cardiac output to walking exercise. Yale J. Biol. Med. 1960, 32, 265.

10. Sarnoff, S. J., and E. Berglund. Ventricular function: I. Starling's law of the heart studied by means of simultaneous right and left ventricular function curves in the dog. Circulation 1954, 9, 706.

11. Sarnoff, S. J., and J. H. Mitchell. The control of the function of the heart in Handbook of Physiology, Section 2: Circulation. Washington, D. C., American Physiological Society, 1962, p. 490.

12. Rushmer, R. F. Effects of nerve stimulation and hormones on the heart; the role of the heart in general circulatory regulation in Handbook of Physiology, Section 2: Circulation. Washington, D. C., American Physiological Society, 1962, p. 537.

13. Frank, O. On the dynamics of cardiac muscle. Amer. Heart J. 1959, 58, 282.

14. Patterson, S. W., H. Piper, and E. H. Starling. The regulation of the heart beat. J. Physiol. (Lond.) 1914, 48, 465.

15. Wiggers, C. J. Studies on the cardiodynamic actions of drugs. I. The application of the optical methods of pressure registration in the study of cardiac stimulants and depressants. J. Pharmacol. exp. Ther. 1927, 30, 217.

16. Wiggers, C. J. Studies on the cardiodynamic actions of drugs. II. The mechanism of cardiac stimulation by epinephrin. J. Pharmacol. exp. Ther. 1927, 30, 233.

17. Reeves, T. J., L. L. Hefner, W. B. Jones, C. Coghlan, G. Prieto, and J. Carroll. The hemodynamic determinants of the rate of change in pressure in the left ventricle during isometric contraction. Amer. Heart J. 1960, 60, 745.

18. Siegel, J. H., and E. H. Sonnenblick. A dynamic index characterizing alterations in the basic state of cardiac muscle. Circulat. Res. In press.

19. Tolman, R. A., and P. G. Young. Slope changes of ventricular pressure curves compared with ventricular function curves. Fed. Proc. 1961, 20, 124.

20. Laurens, P., P. Bouchard, E. Brial, C. Cornu, P. Basculard, and P. Soulié. Bruits et pressions cardio-vasculaires enregistrés in situ à l'aide d'un micromanomètre. Arch. Mal. Coeur 1959, 52, 121.

21. Gleason, W. L., and E. Braunwald. Studies on the first derivative of the ventricular pressure pulse in man. J. clin. Invest. 1962, 41, 80.

22. Braunwald, E., A. Goldblatt, R. T. L. Long, and A. G. Morrow. The krypton ${ }^{85}$ inhalation test for the detection of left-to-right shunts. Brit. Heart J. 1962, 24, 47.

23. Braunwald, E., E. C. Brockenbrough, C. J. Frahm, and J. Ross, Jr. Left atrial and left ventricular pressures in subjects without cardiovascular disease: observations in eighteen patients studied by transseptal left heart catheterization. Circulation 1961, 24, 267.

24. Noble, F. W. Electrical Methods of Blood-pressure Recordings. Springfield, I1l., C. C Thomas, 1953, p. 40 .

25. Weissler, A. M., and H. E. Grode. New observations on the effects of digitalis on ventricular systole in normal individuals (abstract). Clin. Res. 1961 9, 235.

26. Weissler, A. M., and J. V. Warren. Digitalization: an evaluation of the dose-response curve of deslanoside in man (abstract). Circulation 1962, 26, 803.

27. Braunwald, E., R. D. Bloodwell, L. I. Goldberg, and A. G. Morrow. Studies on digitalis. IV. Obser- 
vations in man on the effects of digitalis preparations on the contractility of the non-failing heart and on total vascular resistance. J. clin. Invest. 1961, 40, 52.

28. Kahler, R. L., R. H. Thompson, E. R. Buskirk, R. L. Frye, and E. Braunwald. Studies on digitalis VI: reduction of the post-exercise oxygen debt with digoxin in patients with cardiac disease without heart failure. Circulation 1962, 27, 397.

29. Selzer, A., H. N. Hultgren, C. L. Ebnother, H. W. Bradley, and A. O. Stone. Effect of digoxin on the circulation in normal man. Brit. Heart J. 1959, 21, 335.
30. Williams, M. H., Jr., L. R. Zohman, and A. C. Ratner. Hemodynamic effects of cardiac glycosides on normal human subjects during rest and exercise. J. appl. Physiol. 1958, 13, 417.

31. Dresdale, D. T., Y. Z. Yuceoglu, R. J. Michtom, M. Schultz, and M. Lunger. Effects of Lanatoside C on cardiovascular hemodynamics; acute digitalizing doses in subjects with normal hearts and with heart disease without failure. Amer. J. Cardiol. $1959,4,88$.

32. Selzer, A., and R. O. Malmborg. Hemodynamic effects of digoxin in latent cardiac failure. Circulation 1962, 25, 695. 